\title{
Isolation, Identification and Organoleptic Astringency of Dimeric Proanthocyanidins Occurring in Azuki Beans*
}

\author{
Toshiaki ArIgA and Yasuo AsAo \\ Central Research Laboratories, Kikkoman Corporation, \\ Noda-shi, Chiba 278, Japan
}

Received December 4, 1980

\begin{abstract}
Six kinds of dimeric procyanidins were isolated from azuki beans by combination column chromatographies on Polyamide C-200 and Sephadex LH-20. Judging from the chemical properties, UV absorbance, MS pattern of the isolated procyanidins and the analysis of the products through acid-hydrolysis, they were identified as: a procyanidin with a $\mathrm{C}_{4}-\mathrm{C}_{8}$ linkage $\left(\mathrm{C}_{30} \mathrm{H}_{26} \mathrm{O}_{11}\right)$ and five conformational isomers of Type-B procyanidins with $\mathrm{C}_{4}-\mathrm{C}_{8}$ linkages $\left(\mathrm{C}_{30} \mathrm{H}_{26} \mathrm{O}_{12}\right)$. Each aliquot of aqueous solution $(0.001 \%)$ of dimeric procyanidins tasted astringent. The total content of dimeric procyanidins was assumed to be at least $0.011 \%$ in azuki beans. These compounds may contribute to the astringency of the bean and its products.
\end{abstract}

In general, legume seeds have astringent components which have limited the use of them for food. However, studies on the astringent components are not very advanced, and their principles have not been revealed yet.

In a previous paper, ${ }^{1)}$ we described the occurrence of various kinds of proanthocyanidins in some legume seeds and the organoleptic astringency of partially purified proanthocyanidins. However, their chemical structures and biochemical properties remained unsolved.

Chemical structures of natural proanthocyanidins have not been extensively studied owing to difficulties in isolation and characterization. Recent advances in chromatographic and analytical techniques enabled determination of the chemical structures of lower oligomers of proanthocyanidins. Several studies $^{2 \sim 4)}$ have been conducted on chemical structures of dimeric proanthocyanidins in plants during the last twenty years. Following recent advances in their chemistry, it is now possible to identify some of the procyanidins occurring in legume seeds.

This paper describes the isolation, identifi-

* Studies on Astringent Components in Legume Seeds. Part II. cation, and organoleptic astringency of dimeric procyanidins occurring in azuki beans.

\section{MATERIALS AND METHODS}

Raw materials. Japanese azuki beans (Vigna angularis Ohwi et Ohashi, var. Dainagon) were purchased from a local market.

Extraction. The extraction of proanthocyanidins was carried out in the same way as described in the previous paper. ") The aqueous acetone extracts were saturated with $\mathrm{NaCl}$ to salt out the acetone. ${ }^{5}$ The acetone phase was washed with the aqueous phase of the extraction solvent preliminarily saturated with $\mathrm{NaCl}$. The washed acetone phase was evaporated in vacuo at $40^{\circ} \mathrm{C}$ and reextracted with $\mathrm{EtOH}$ to give the crude phenolic extract.

Isolation of proanthocyanidins from azuki beans. The crude phenolic extract was percolated through a column of Polyamide C-200 $(2.5 \times 39 \mathrm{~cm})$ preliminarily swollen with EtOH. The column was washed with $\mathrm{EtOH}(1000 \mathrm{ml})$ and then eluted with $\mathrm{MeOH}(1000 \mathrm{ml})$. The eluate was fractionated into 100 tubes, $10 \mathrm{ml}$ in each, and roughly analyzed by TLC. Proanthocyanidin-containing fractions were combined and further chromatographed on Sephadex LH-20 $(2.2 \times 117.5 \mathrm{~cm})$ with EtOH. $\left.{ }^{4}\right)$ Appropriate fractions were combined and rechromatographed on the same column with ethanolpropan-1-ol $(4: 1 \mathrm{v} / \mathrm{v})$ to yield proanthocyanidins which ran as single compact spots on two dimensional cellulose TLC. 
Two dimensional cellulose thin-layer chromatography. The fractions of eluate were analyzed by two dimensional TLC. The TLC was carried out on Avicel SF cellulose by successive development with $5 \% n$-butanol and $n$ butanol-acetic acid-water $(6: 1: 2.2){ }^{7}{ }^{7}$ Detection of flavans was done with vanillin- $\mathrm{HCl}$ reagent and $\mathrm{FeCl}_{3}-\mathrm{K}_{3} \mathrm{Fe}$ $(\mathrm{CN})_{6}$ reagent and $\mathrm{UV}$ absorbancy. ${ }^{8}$

Hydrolysis of proanthocyanidins with hydrochloric acid. Controlled-hydrolysis of proanthocyanidins $(5 \mathrm{mg})$ was carried out by treating them with $0.1 \mathrm{~N}$-hydrochloric acid in EtOH at room temperature. ${ }^{4 /}$ The conversion of leucoanthocyanidin to anthocyanidin was done at $98^{\circ} \mathrm{C}$ with $4 \% \mathrm{HCl}$ in $80 \% n$-BuOH. The anthocyanidin formation was estimated by absorbance at $550 \mathrm{~nm}{ }^{6}$ The pigments produced were identified by paper chromatography on Toyo $51_{\mathrm{A}}$ using Forestal's solvent. ${ }^{9)}$

Preparation of proanthocyanidin methyl ethers for spectroscopy. Proanthocyanidin methyl ethers were prepared by treating proanthocyanidins $(5 \mathrm{mg}$ ) in methanol with excess diazomethane in ethyl ether at $-10^{\circ} \mathrm{C}$ for $2 \mathrm{hr}$, followed by shifting up to $20^{\circ} \mathrm{C}$ for $18 \mathrm{hr}$. After eliminating the solvent in vacuo, the methyl ethers were purified by means of TLC on silica gel with a 1:1 mixture $(\mathrm{v} / \mathrm{v})$ of chloroform and ethyl acetate as a developing solvent. The bands of methyl ethers were scraped off together and extracted with acetone. The extract was dried in vacuo to give an amorphous solid (ca. $2 \sim 3 \mathrm{mg}$ ).

Preparation of proanthocyanidin acetyl derivatives. Proanthocyanidin acetyl derivatives were prepared by dissolving proanthocyanidins ( $5 \mathrm{mg}$ ) or their methyl ethers $(2 \mathrm{mg})$ in aliquots of water-free pyridine and making them react with acetic anhydride. After $20 \mathrm{hr}$ at $20^{\circ} \mathrm{C}$, the precipitates were obtained by addition of ice-cold water. They were dissolved again in acetone and purified by means of TLC on silica gel developed with tolueneacetone $(8: 2){ }^{10)}$ The bands demonstrated on TLC were extracted with acetone in the same way as described before. ") The extract was dried in vacuo to give an amorphous solid (ca. $1 \sim 3 \mathrm{mg}$ ).

Mass spectroscopy. Mass spectra were obtained using a Hitachi double focus mass spectrometer model RMU-7M.
Sensory evaluation test. The sensory evaluation test was carried out in the same way as reported previously. ${ }^{1)}$

\section{RESULTS AND DISCUSSION}

Azuki beans contained much impurities which interfered with the clear separation of proanthocyanidins on TLC or on column chromatography. In order to remove these impurities, it seemed that salting out the aqueous acetone extract with $\mathrm{NaCl}$ was very effective.

On two dimensional TLC on Avicel SF cellulose, a number of unknown flavans were demonstrated in the EtOH solution of the crude phenolic extract.

These polyphenols were adsorbed at the top part of the Polyamide C-200 column. Simple phenols could be eliminated by elution with EtOH. On the other hand, dimeric proanthocyanidins were eluted with $\mathrm{MeOH}$. The elution pattern is shown in Fig. 1. Polyphenols other than dimeric proanthocyanidins could not be eluted with $\mathrm{MeOH}$.

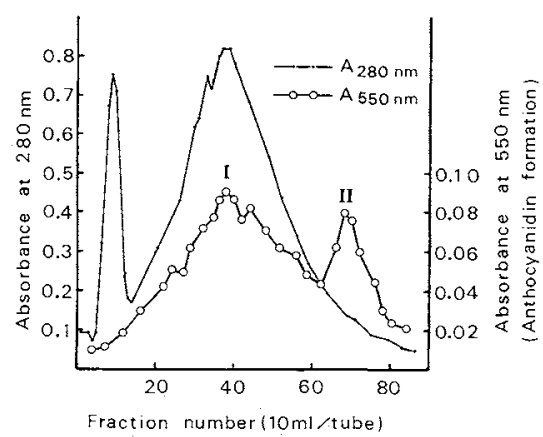

Fig. 1. Chromatography of Phenolics from Azuki Beans on Polyamide C-200.

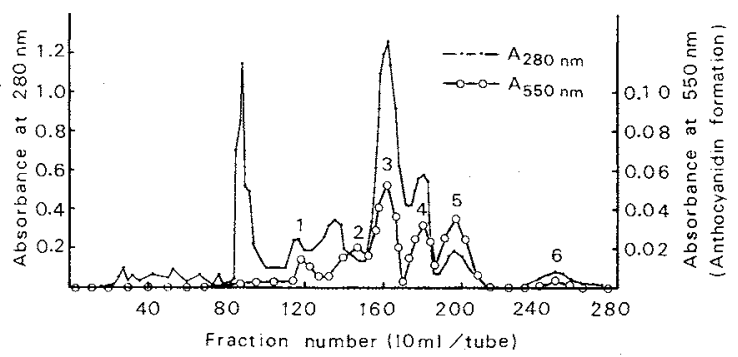

FIG. 2. Chromatography of Phenolics from Azuki Beans on Sephadex LH-20. 
The methanol eluate containing dimeric proanthocyanidins was dried in a rotary evaporator. The residue was dissolved again in ethanol for Sephadex LH-20 column chromatography. Figure 2 shows the results of the column chromatography. Six peaks of proanthocyanidin dimers were separated from each other. Each peak was rechromatographed on the same column with ethanolpropan-1-ol $(4: 1 \mathrm{v} / \mathrm{v})$. Each peak thus rechromatographed showed a single spot on two dimensional TLC.

The UV spectrum of the substance purified from peak -5 was similar to that of $(+)$ catechin or (-)epi-catechin and showed an absorption maximum at $281 \mathrm{~nm}$. No absorption peak was observed above $300 \mathrm{~nm}$ not only within the UV range but also in the visible range. Hydrolysis of the substance purified from peak-5 with $0.1 \mathrm{~N}$-hydrochloric acid in ethanol yielded $(+)$ catechin, which was confirmed by paper chromatography. ${ }^{4)}$ Cyanidin was formed when the substance was treated with $4 \%$ $\mathrm{HCl}$ in $80 \% n$-butanol, which was also confirmed by paper chromatography. ${ }^{9)}$ In MS (Fig. 3) of the methyl derivative of the unidentified procyanidin prepared from peak-5, the molecular ion appeared at $\mathrm{m} / \mathrm{z}$ 690. The spectrum also showed characteristic peaks at $m / z$ 672, 654, 511, 493, 492, 479, 477, 461, 331, $327,299,191,180,179,167,165,151$ and 137. This spectrum coincided with that of a Type-B procyanidin. ${ }^{11)}$ On MS of the acetyl derivative of the substance prepared from peak -5 , the

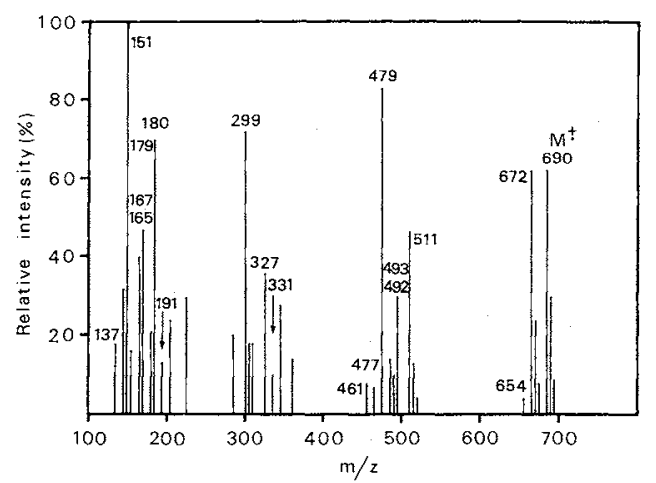

FIG. 3. Mass Spectrum of Octamethyl-procyanidin from Peak-5. molecular ion appeared at $\mathrm{m} / z \quad 998$ which corresponded to the decaacetyl derivative of a Type-B procyanidin. ${ }^{11)}$

Other unidentified proanthocyanidins purified from peak-2, 3, 4 and 6 showed quite similar characteristics to that of proanthocyanidin from peak-5 with respect to UV absorbance, MS pattern and anthocyanidin formation. However, they showed different retention times on Sephadex LH-20 chromatography and their methyl derivatives also showed different $R f$ values on TLC.

Judging from these results, it seemed that these five proanthocyanidins, peak-2, 3, 4, 5, and 6 , were conformational isomers of Type-B procyanidins $\left(\mathrm{C}_{36} \mathrm{H}_{26} \mathrm{O}_{12}\right)$.

On the other hand, hydrolysis of the unidentified proanthocyanidin from peak-1 yielded cyanidin and an unidentified flavan which was supposed to be flavan-3-ol. In the mass spectrum of the methyl derivative of the unknown procyanidin prepared from peak-1, the molecular ion appeared at $m / z$ 674. Additional acetylation treatment of it gave a product of which the MS showed the molecular ion at $\mathrm{m} / \mathrm{z}$ 744 (Fig. 4). The MS fragmentation pattern of the latter was in accord with that of procyanidin $2\left(\mathrm{C}_{36} \mathrm{H}_{26} \mathrm{O}_{11}\right){ }^{3}$ ) This result indicated that the unidentified proanthocyanidin from peak-1 may perhaps be one of conformational isomers of procyanidin 2. Perhaps this is the first report of the occurrence of procyanidin 2 in food stuffs.

Table I summarizes the characteristics of

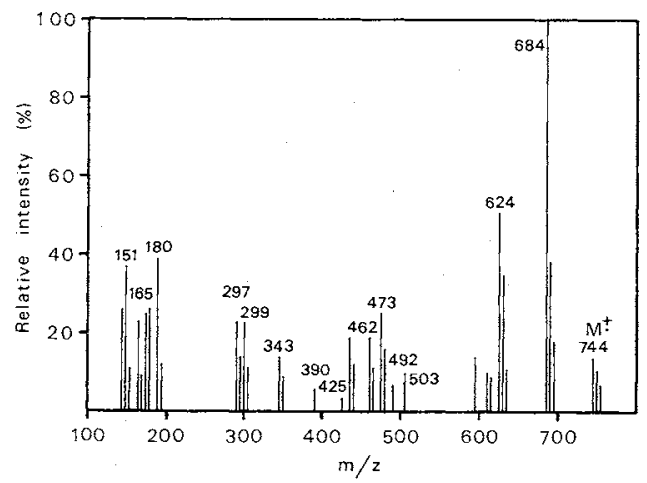

FIG. 4. Mass Spectrum of Diacetyl-heptamethylprocyanidin from Peak-1. 
Table I. Characterization of Procyanidins from Azuki Beans

\begin{tabular}{|c|c|c|c|c|c|c|}
\hline & P-1 & P-2 & P-3 & P-4 & P-5 & P-6 \\
\hline $\begin{array}{l}\text { Sephadex LH- } 20^{a} \\
\text { chromatography }\end{array}$ & 1.5 & 1.8 & 2.0 & 2.1 & 2.3 & 3.0 \\
\hline $\begin{array}{l}R f^{b} \text { of } \\
\text { methyl ethers }\end{array}$ & 0.59 & 0.58 & 0.56 & 0.37 & 0.31 & 0.27 \\
\hline $\begin{array}{l}m / z\left(\mathrm{M}^{+}\right) \text {of } \\
\text { methyl ethers }\end{array}$ & 674 & 690 & 690 & 690 & 690 & 690 \\
\hline $\begin{array}{l}\text { Suggested } \\
\text { molecular formula }\end{array}$ & $\mathrm{C}_{30} \mathrm{H}_{26} \mathrm{O}_{1 \mathrm{I}}$ & $\mathrm{C}_{30} \mathrm{H}_{26} \mathrm{O}_{12}$ & $\mathrm{C}_{30} \mathrm{H}_{26} \mathrm{O}_{12}$ & $\mathrm{C}_{30} \mathrm{H}_{26} \mathrm{O}_{12}$ & $\mathrm{C}_{30} \mathrm{H}_{26} \mathrm{O}_{12}$ & $\mathrm{C}_{30} \mathrm{H}_{26} \mathrm{O}_{12}$ \\
\hline
\end{tabular}

a Ratio of elution volume to elution volume of $(+)$ catechin.

$b$ Silica HPTLC: solvent, $\mathrm{CHCH}_{3}-\operatorname{EtOAc}(1: 1 \mathrm{v} / \mathrm{v})$.

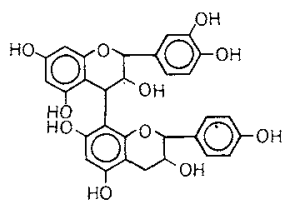

$P-1$

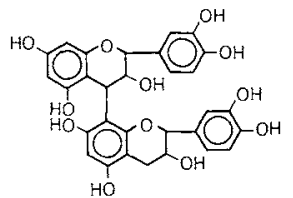

$\mathrm{P}-2, \mathrm{P}-3, \mathrm{P}-4, \mathrm{P}-5, \mathrm{P}-6$ (Conformational isomers)

FIG. 5. Suggested Structures for Procyanidins from Azuki Beans.

the six procyanidins isolated from azuki beans. And Fig. 5 illustrates the suggested structures for them.

The organoleptic astringency of these compounds was evaluated by five judges. All of them judged that each aqueous $0.0010 \%$ procyanidin solution tasted astringent. This suggested that these compounds may taste more astringent than any other natural compounds. ${ }^{12)}$

Since $107 \mathrm{mg}$ of dimeric procyanidins was actually isolated from $1 \mathrm{~kg}$ of azuki beans, the total content of dimeric procyanidins was assumed to be, at least, $0.0107 \%$.

In conclusion, these compounds may perhaps contribute to the astringency of azuki beans and their products.

Acknowledgments. The authors wish to express their thanks to Dr. T. Yokotsuka of this corporation for his kind advice and to Dr. N. Iguchi of these laboratories for his encouragement. Thanks are also due to Dr. H. Sugimoto of these laboratories for the critical revision of this paper, and to Dr. M. Sasaki and Mr. N. Nunomura of the same organization for MS measurements.

\section{REFERENCES}

1) T. Ariga, Y. Asao, H. Sugimoto and T. Yokotsuka, Agric. Biol. Chem., 45, 2705 (1981).

2) T. A. Geissman and H. F. K. Dittmar, Phytochemistry, 4, 359 (1965).

3) K. Weinges, K. Goritz and F. Nader, Liebigs Ann. Chem., 715, 164 (1968).

4) R. S. Thompson, D. Jacques, E. Haslam and R. J. N. Tanner, J. Chem. Soc. Perkin I, 11, 1387 (1972).

5) W. T. Jones, R. B. Broadhurst and J. W. Lyttleton, Phytochemistry, 15, 1407 (1976).

6) H. E. Hillis, J. Sci. Food Agric., 10, 63 (1959).

7) J. P. Van Buren, G. Senn and H. Neukom, J. Food Sci., 31, 964 (1966).

8) T. Nakabayashi, Nippon Shokuhin Kogyo Gakkaishi, 15, 21 (1968).

9) E. C. Bate-Smith, Biochem. J., 58, 122 (1954).

10) A. G. H. Lea and C. F. Timberlake, J. Sci. Food Agric., 25, 1537 (1974).

11) H. W. H. Schmidt and H. Neukom, J. Agric. Food Chem., 17, 344 (1969).

12) M. Nakagawa, Nippon Shokuhin Kogyo Gakkaishi, 19, 531 (1972). 